\title{
CAMA
}

Centre for Applied Macroeconomic Analysis

\section{Monetary Policy with a State-Dependent Inflation Target in a Behavioral Two-Country Monetary Union Model}

\section{CAMA Working Paper 89/2020 October 2020}

\section{Christian R. Proaño}

Otto-Friedrich-Universität Bamberg, Germany

Centre for Applied Macroeconomic Analysis, ANU

\section{Benjamin Lojak}

Otto-Friedrich-Universität Bamberg, Germany

\section{Abstract}

In this paper we study the implementation of a state-dependent inflation target in a twocountry monetary union model characterized by boundedly rational agents. In particular, we use the spread between the actual policy rate (which is constrained by the zero-lowerbound) and the Taylor rate (which can become negative) as a measure for the degree of ineffectiveness of conventional monetary policy as a stabilizing mechanism. The perception of macroeconomic risk by the agents is assumed to vary according to this measure by means of the Brock-Hommes switching mechanism. Our numerical simulations indicate a) that a state-dependent inflation target may lead to a better macroeconomic and inflation stabilization, and b) the perceived risk-sharing among the monetary union members influences the financing conditions of the member economies of the monetary union. 


\section{Keywords}

Monetary Policy, Monetary Unions, Zero Lower Bound, Inflation Targets, Behavioral Macroeconomics

\section{JEL Classification}

E52, E7, F020

\section{Address for correspondence:}

(E) cama.admin@anu.edu.au

\section{ISSN 2206-0332}

The Centre for Applied Macroeconomic Analysis in the Crawford School of Public Policy has been established to build strong links between professional macroeconomists. It provides a forum for quality macroeconomic research and discussion of policy issues between academia, government and the private sector.

The Crawford School of Public Policy is the Australian National University's public policy school, serving and influencing Australia, Asia and the Pacific through advanced policy research, graduate and executive education, and policy impact. 


\title{
Monetary Policy with a State-Dependent Inflation Target in a Behavioral Two-Country Monetary Union Model
}

\author{
Christian R. Proaño*a,b and Benjamin Lojak ${ }^{\mathrm{a}}$ \\ ${ }^{a}$ Otto-Friedrich-Universität Bamberg, Germany \\ ${ }^{\mathrm{b}}$ Centre for Applied Macroeconomic Analysis, Australian National University
}

August 30, 2020

\begin{abstract}
In this paper we study the implementation of a state-dependent inflation target in a two-country monetary union model characterized by boundedly rational agents. In particular, we use the spread between the actual policy rate (which is constrained by the zero-lower-bound) and the Taylor rate (which can become negative) as a measure for the degree of ineffectiveness of conventional monetary policy as a stabilizing mechanism. The perception of macroeconomic risk by the agents is assumed to vary according to this measure by means of the Brock-Hommes switching mechanism. Our numerical simulations indicate a) that a state-dependent inflation target may lead to a better macroeconomic and inflation stabilization, and b) the perceived risk-sharing among the monetary union members influences the financing conditions of the member economies of the monetary union.
\end{abstract}

JEL Codes: E52, E7, F020

Keywords: Monetary Policy, Monetary Unions, Zero Lower Bound, Inflation Targets, Behavioral Macroeconomics

${ }^{*}$ E-mail: christian.proano@uni-bamberg.de. We would like to thank Michael Roos, Lena Dräger, Ulrich Fritsche, Joep Lustenhouwer, Emanuel Gasteiger and Sandra Niemeier for helpful comments and suggestions on previous drafts of this paper, as well as Berit Rohde for excellent research assistance. 


\section{Introduction}

The definition of the inflation target is a key element of the monetary policy strategy of most central banks. While this is a truism in normal times it is even more important in periods where the zero lower bound (ZLB) on nominal interest rates becomes binding and the expectations channel of monetary policy becomes even more relevant, and the change of the target itself may be a tool used by central banks.

In his seminal contribution Krugman (1998) already raised the question (in the context of Japan's long-lasting economic slump) of whether a temporary increase of the central bank's inflation target would be advisable in situations where nominal interest rates are constrained by the ZLB. The ultra-low inflation and nominal interest rates period following the Global Financial Crisis have also led researchers such as Blanchard et al. (2010), Ball (2013), and De Grauwe and Ji (2019) also to call for a higher inflation target than the $2 \%$ pursued by most central banks as a mean to increase the public's inflation expectations and thus, by extension, stimulate aggregate demand. In their view, the advantages in terms of macroeconomic flexibility related with higher inflation targets of say $4 \%$ clearly outweigh the possible costs of a higher long-run inflation rate. This view is not uncontested. For instance, Schmitt-Grohe and Uribe (2010) and Coibion et al. (2012) argue that a change in the inflation target is not a convenient stabilization tool since it does not necessarily reduce the costs arising from the ZLB. They further claim that low inflation targets, close to zero, reduce the probability of reaching the zero bound on interest rates. Additionally, Eggertsson and Woodford (2003) show that raising the inflation target increases the number of periods when the policy rate hits the ZLB, due to a reduction of the natural rate of interest which is conditional for the ZLB to become a binding constraint. Further, Coibion et al. (2012) argue that the optimal rate of inflation is unlikely to be significantly higher than $2 \%$ even if possible ZLB episodes, which are assumed to happen in $1 \%$ of the time, are taken into account. In contrast, Chung et al. (2012) argue that there are various arguments for much more often ZLB periods than what was assumed in previous studies. In this light, Dordal i Carreras et al. (2016) also find that if the distribution of ZLB durations is modelled in a more realistic manner, the optimal inflation ranges between $1.5 \%$ and $4 \%$.

Various researchers have already investigated or at least argued for a state-dependent definition of the monetary policy target. Evans (2010), while stressing the advantages of pricelevel targeting relative to the more standard inflation targeting, suggests the implementation of a state-contingent price-level target which would be higher as long as the economy is in a liquidity trap. Once the higher price-level path is achieved with confidence, he argues, 
the monetary policy strategy would return a targeting of $2 \%$ inflation over the medium run. Similarly, Bernanke (2017) argues in favor of a "temporary price-level target" that would kick in only when rates are constrained by the ZLB. Alternatively, Kiley and Roberts (2017) propose an inflation targeting interest rate which takes into account the foregone accommodation - measured by a "shadow rate rule" - because of the ZLB. This "shadow rate rule" would reflect the cumulative deviations of inflation and output from their respective targets during the ZLB episode, being this history-dependent in a similar way as a price-level targeting rule would be at least during the ZLB period. In a similar approach, Proaño and Lojak (2020) use the ZLB policy rate gap - defined as the spread between the policy rate and the hypothetical Taylor rule rate which would prevail if the ZLB was not binding as a measure for lack of conventional monetary policy accommodation which affects the risk perception of the market participants, leading to higher risk premia and thus to a deterioration of the financing conditions of households and the government which in turn prolongs the ZLB episode.

To the best of our knowledge, these and the other studies in this strand of the literature have focused on a single closed economy, abstracting from the international dimension. Further, they have not analyzed the case of a monetary union where more than one country is subject to the same monetary policy and thus to the same inflation target. As the "close but below 2\%" inflation target by the European Central Bank (ECB) may represent a significant constraint for the macroeconomic flexibility of at least some of the economies within the euro area, it is worthwhile to investigate the potential benefits and drawbacks of a possible varying inflation target in a monetary union context. In particular, we focus on the risk-sharing aspect of monetary unions such as the euro area (Jaumotte and Sodsriwiboon, 2010, De Grauwe and Ji, 2013 Proaño et al., 2014, Proaño and Lojak, 2017), and how the risk premium charged on government bonds can be affected by the ZLB.

The remainder of the paper is organized as follows. In section 2 we describe the behavioral two-country monetary union model based on Proaño and Lojak (2020) and similar in spirit to Bertasuite et al. (2020). In section 3 we discuss the results of our numerical analysis both concerning the short-run dynamics of the model as well as its medium-run properties under a constant inflation target and under a state-dependent inflation target. We undertake a robustness analysis of our findings in section 4 , also delivering additional insights. Finally, we draw some conclusions from this study in section 5 . 


\section{The Model}

We consider a two-country monetary union which is populated by a continuum of agents on the interval $[0,1]$, a segment $[0, n]$ residing in a country labeled $H$ (ome), the other segment living in the other country labeled $F$ (oreign). There is no migration between regions. Both countries are assumed to produce tradable consumption goods, which are however considered as imperfect substitutes due to a standard home bias argument, and to feature otherwise the same characteristics concerning the structure of their behavioral equations. The governments in the Home and Foreign regions dictate their fiscal policy in an independent and sovereign manner, financing their expenditures through the raise of taxes and the issuance of one-period bonds. Furthermore, there is a single monetary policy authority (the monetary union's central bank or MUCB) which sets the riskless short-term interest rate which acts as reference for the pricing of the Home and Foreign government bonds. Moreover, the Foreign country's government will be assumed to be considered as more solvent by the market's participants, becoming in the limit a "safe haven" for financial capital. ${ }^{1}$

More specifically, we consider a two-country version of the behavioral macroeconomic framework studied in Proaño and Lojak (2020). As there we specify here the behavioral equations of the macroeconomic variables in terms of log deviations from their respective long-run equilibrium values to focus on the nonlinear dynamics of the agents' boundedly rational perceptions. Accordingly, for any given variable $X_{t}$, it holds

$$
X_{t}=\exp \left(\ln (\mathbb{X})+x_{t}\right)
$$

where $X_{t}$ represents the level of the variable $X_{t}, \mathbb{X}$ its (time-invariant) steady state value and $x_{t}$ the $\log$ deviation of $X_{t}$ from $\mathbb{X}$.

\subsection{Households and Firms}

As it is widely known, the households' consumption problem can be divided (under the assumption of timely additive preferences) into two independent economic decisions: the contemporaneous choice of the optimal composition of the consumption bundle or aggregate composite consumption good, and the determination of this aggregate composite good over time. ${ }^{2}$ From this perspective, it is intuitive to assume a standard optimizing behavior by the

\footnotetext{
${ }^{1}$ The following exercise could be related in the EU case to the analysis of the interaction between Germany and Italy or Spain, for example.

${ }^{2}$ However, these two economic decisions demand different degrees of rationality from the economic agents as they imply different degrees of complexity for their respective optimization: While the intra-temporal
} 
economic agents for the intra-temporal decision problem, while specifying the intertemporal decision problem in a more "behavioral" manner. Therefore, concerning the intra-temporal decision problem, Home and Foreign households are assumed to be able to choose in each period in an optimal manner the composition of their aggregate consumption bundle

$$
C_{t}^{H}=\left[\gamma_{h}^{1 / a}\left(C_{h, t}\right)^{(a-1) / a}+\left(1-\gamma_{h}^{1 / a}\right)\left(C_{f, t}\right)^{(a-1) / a}\right]^{a /(a-1)}
$$

with $a>1$ denoting the price elasticity of goods demand and $\frac{1}{2}<\gamma<1$ representing the degree of home bias towards domestic consumption. Home households minimize the cost of achieving a given level of $C_{t}^{H}$ under the cost constraint $P_{t}^{h} C_{h, t}+P_{t}^{f} C_{f, t}$ taking $P_{t}^{h}$ and $P_{t}^{f}$ (the average price levels of the domestically and foreign produced consumption goods $C_{h, t}$ and $C_{f, t}$, respectively) as given, by demanding in each period an amount of home- and foreign produced goods determined by

$$
C_{h, t}^{H}=\gamma_{h}\left(\frac{P_{t}^{h}}{P_{c, t}^{H}}\right)^{-a} C_{t}^{H}, \quad \text { and } \quad C_{f, t}^{H}=\left(1-\gamma_{h}\right)\left(\frac{P_{t}^{f}}{P_{c, t}^{H}}\right)^{-a} C_{t}^{H}=M_{t}^{H}=X_{t}^{F}
$$

where $M_{t}^{H}$ represents Home's imports (Foreign's exports $X_{t}^{F}$ ) and $P_{c, t}^{H}$ is the corresponding aggregate Consumer Price Index in the Home country defined as

$$
P_{c, t}^{H} \equiv\left[\gamma_{h}\left(P_{t}^{h}\right)^{1-a}+\left(1-\gamma_{h}\right)\left(P_{t}^{f}\right)^{1-a}\right]^{1 /(1-a)} .
$$

Assuming an analogous behavior of the Foreign households, their optimal demand for Home- and Foreign-produced goods is given by

$$
C_{f, t}^{F}=\gamma_{f}\left(\frac{P_{t}^{f}}{P_{c, t}^{F}}\right)^{-a} C_{t}^{F}, \quad \text { and } \quad C_{h, t}^{F}=\left(1-\gamma_{f}\right)\left(\frac{P_{t}^{h}}{P_{c, t}^{F}}\right)^{-a} C_{t}^{F}=M_{t}^{F}=X_{t}^{H},
$$

respectively, where $M_{t}^{F}$ represents Foreign's imports (Home's exports $X_{t}^{H}$ ) with

$$
P_{c, t}^{F} \equiv\left[\gamma_{f}\left(P_{t}^{f}\right)^{1-a}+\left(1-\gamma_{f}\right)\left(P_{t}^{h}\right)^{1-a}\right]^{\frac{1}{1-a}}
$$

being the aggregate Consumer Price Index in the Foreign country.

Concerning the determination of the aggregate composite good over time, as in Proaño and Lojak (2020) we assume for the evolution of (the log deviations of) aggregate consumption $c_{t}^{k}$, the following behavioral Euler-type specification

$$
c_{t}^{k}=\tilde{E}_{t}\left[c_{t+1}^{k}\right]-\sigma^{-1}\left(R_{t}^{k}-E_{t}\left[\pi_{c, t+1}^{k}\right]-r^{o}\right)+\varepsilon_{t}^{k, c}, \quad k=\{H, F\}
$$

problem can be solved in a straightforward manner if all goods prices are publicly known, the optimization of the intertemporal problem requires a much larger knowledge or information set to be employed by the economic agents, as well as a higher degree of rationality. 
where $R_{t}^{k}$ is the nominal (risky) interest rate, $r^{o}$ the steady-state real interest rate, $\varepsilon_{t}^{c}$ is a stochastic shock (to be defined further below) and $\tilde{E}_{t}\left[c_{t+1}^{k}\right]$ and $E_{t}\left[\pi_{c, t+1}^{k}\right]$ represent the households' average subjective expectation of their future consumption $c_{t+1}$ and of the future price inflation (measured in CPI terms), respectively. Eq.(6) can be thus understood as a behavioral Euler consumption equation under the assumption of behavioral expectations by the households.

As Proaño and Lojak (2020) (see also De Grauwe, 2012), we assume that the aggregate expectations of households concerning their consumption expectations are determined through

$$
\tilde{E}_{t}\left[c_{t+1}\right]=\omega_{t}^{p} E_{t}^{p}\left[c_{t+1}\right]+\left(1-\omega_{t}^{p}\right) E_{t}^{o}\left[c_{t+1}\right]
$$

where $E_{t}^{p}\left[c_{t+1}\right]=\alpha_{c} y_{t-1}\left(\right.$ with $\left.0<\alpha_{c}<1\right), E_{t}^{o}\left[c_{t+1}\right]=0$ and $\omega_{t}^{p}$ being the endogenously determined relative weight of the persistent expectations rule to be defined below. By the same token, aggregate inflation expectations are given by

$$
\tilde{E}_{t}\left[\pi_{t+1}\right]=\omega_{t}^{p} E_{t}^{p}\left[\pi_{t+1}\right]+\left(1-\omega_{t}^{p}\right) E_{t}^{o}\left[\pi_{t+1}\right]
$$

where $E_{t}^{p}\left[\pi_{t+1}\right]=\pi_{t-1}, E_{t}^{o}\left[\pi_{t+1}\right]=\pi^{*}$ and $\omega_{t}^{p}$ being the same endogenously determined relative weight of the persistent expectations as before.

Firms produce tradable goods and adjusts their prices according to a standard forwardlooking Phillips curve relationship

$$
\pi_{t}^{k}=\kappa y_{t}^{k}+\tilde{E}_{t}\left[\pi_{t+1}^{k}\right]+\epsilon_{t}^{k, \pi}
$$

where $\kappa$ is the slope of the Phillips curve, $y_{t}^{k}=\log \left(Y_{t}^{k} / \mathbb{Y}_{t}^{k}\right)$ the output gap (defined as the

$\log$ deviation of current output from its steady state level), and $\varepsilon_{t}^{\pi}$ is a cost-push shock to be defined further below.

$$
P_{t}^{h}=\left(1+\pi_{t}^{H}\right) P_{t-1}^{h} ; \quad P_{t}^{f}=\left(1+\pi_{t}^{F}\right) P_{t-1}^{f}
$$

\subsection{The Government Sector}

Cyclical government spending is assumed to be determined by the following rule:

$$
g_{t}^{k}=-\phi_{g y} y_{t-1}^{k}-\phi_{b}^{k}\left(\frac{B_{t-1}^{k}}{Y_{t-1}^{k}}-\psi\right)
$$

The period budget constraint of the government in real terms is given by

$$
B_{t}^{k}=\frac{\left(1+R_{t-1}^{k}\right)}{\left(1+\Pi_{t}^{k}\right)} B_{t-1}+G_{t}^{k}-T_{t}^{k} .
$$


Putting all pieces together, the output gap $y_{t}$ can thus be derived by log-linearizing the market clearing identity $Y_{t}=C_{t}+G_{t}$ around the level of potential output $\mathbb{Y}$. Therefore, aggregate demand in terms of deviations around the potential level becomes

$$
y_{t}^{H}=\frac{\mathbb{C}}{\mathbb{Y}} c_{t}^{H}+\frac{\mathbb{G}}{\mathbb{Y}} g_{t}^{H}+\frac{\mathbb{X}}{\mathbb{Y}} x_{t}^{H}-\frac{\mathbb{M}}{\mathbb{Y}} m_{t}^{H}
$$

where $\theta_{c}=\mathbb{C} / \mathbb{Y}$ is the households' exogenous propensity to consume and $\theta_{g}=\mathbb{G} / \mathbb{Y}$ is the government's long-term expenditure-GDP ratio.

Straightforward algebra yields

$$
y_{t}^{H}=\theta_{c} \gamma c_{t}^{H}+\theta_{g} g_{t}^{H}+2 a \theta_{c}(1-\gamma)\left(p_{t}^{f}-p_{t}^{h}\right)+\theta_{c}(1-\gamma) c_{t}^{F}
$$

where $p_{t}^{f}-p_{t}^{h}:=\pi_{t}^{F}-\pi_{t}^{H}+\ln P_{t-1}^{f}-\ln P_{t-1}^{h}$.

\subsection{The Monetary Union Interest Policy Rule}

The evolution of the short-term policy interest rate set by the central bank of the monetary union is assumed to determined by

$$
i_{t}=\phi_{i} i_{t-1}+\left(1-\phi_{i}\right)\left[i_{o}+\phi_{\pi}\left(\pi_{t}^{M U}-\pi_{t}^{\star}\right)+\phi_{y} y_{t}^{M U}\right]+\epsilon_{t}^{i} \quad \forall i_{t} \geq 0
$$

with

$$
\begin{aligned}
& \pi_{t}^{M U}=\omega_{H} \pi_{t-1}^{H}+\left(1-\omega_{H}\right) \pi_{t-1}^{F} \\
& y_{t}^{M U}=\omega_{H} y_{t-1}^{H}+\left(1-\omega_{H}\right) y_{t-1}^{F}
\end{aligned}
$$

where $\omega_{H}$ and $\omega_{F}=1-\omega_{H}$ represent the relative economic size of country $H$ and $F$, respectively, in the monetary union.

As in Proaño and Lojak (2020) we consider the following specification for the inflation target

$$
\pi_{t}^{*}=\left(1-\nu_{\pi^{*}}\right) \pi_{t-1}^{*}+\nu_{\pi^{*}}\left(\pi^{*}+i_{t-1}-i_{t-1}^{T}\right)
$$

According to this specification, starting from the steady state where $\pi_{t}^{*}=\pi^{*}$, the inflation target $\pi_{t}^{*}$ would be increased at the ZLB in proportion to $i_{t}-i_{t-1}^{T}$, i.e., by the ZLB policy gap, and would return to $\pi^{*}$ after the ZLB is no longer relevant (with $i_{t}-i_{t-1}^{T}=0$ ) with a velocity determined by $\nu_{\pi^{*}}$. As previously mentioned, a similar approach has been proposed by Bernanke (2017) and Kiley and Roberts (2017). 


\subsection{Risk Premia and Animal Spirits}

As already mentioned in the introduction, the monetary union risk-sharing aspect is one of the focal points of our analysis.

We consider two alternative specifications for the risk-premium over the risk-free rate. Under the first specification the common risk premium for Home and Foreign is

$$
\zeta_{t}^{k}=\xi_{a} A_{t-1}-\xi_{y} y_{t-1}^{M U}+\xi_{b}\left(b_{t-1}^{M U}-\bar{b}\right)+\xi_{\pi}\left|\tilde{E}_{t}\left[\pi_{t+1}^{M U}\right]-\pi^{*}\right|, \quad \text { for } \quad k=\{H, F\}
$$

where $\xi_{a}, \xi_{y}, \xi_{b}$ and $\xi_{\pi}$ are positive coefficients, and $b_{t-1}^{M U}$, the average government debt-toGDP ratio is determined analogously to eqs. (16) and (17). As in Proaño and Lojak (2020) (see also Adrian et al., 2010 and Quint and Rabanal, 2014), we assume that the risk premium on risky bonds is a negative function of the monetary union's averages of the output gap, and a positive function of the deviation of the debt-to-GDP ratio from its long-term target and of the absolute deviation of the aggregate inflation expectations from the central bank's target $\pi^{*}$ (as both positive and negative deviations may be considered equally "bad" by the economic agents). Further, as in Proaño and Lojak (2020) we include an "animal spirits variable" $A_{t}$ which represents the perception of the majority of market participants concerning the undone accommodation of conventional monetary policy due to the ZLB. This measure for ZLB-related "animal spirits" is given by

$$
A_{t}=\omega_{t}^{p}-\omega_{t}^{o}, \quad A_{t} \in[-1,1]
$$

where $\omega_{t}^{p}$ and $\omega_{t}^{o}$ are the relative populations of agents using the "persistent" and the "steadystate" expectations $E_{t}^{p}[\cdot]$ and $E_{t}^{o}[\cdot]$, respectively which are determined through a binary choice approach (see Brock and Hommes, 1997), namely

$$
\begin{aligned}
& \omega_{t}^{p}=\frac{\exp \left[\mu\left(i_{t}-i_{t}^{T}\right)\right]}{1+\exp \left[\mu\left(i_{t}-i_{t}^{T}\right)\right]} \\
& \omega_{t}^{o}=1-\omega_{t}^{p}
\end{aligned}
$$

with the parameter $\mu \geq 0$ being the intensity of choice. In normal times, where the ZLB is not binding, $i_{t}=i_{t}^{T}$, the "animal spirits" measure $A_{t}$ becomes zero, playing therefore no role in the determination of $\zeta_{t}^{M U}$, see eq. (19). At the ZLB, on the contrary, $i_{t}=0$, while $i_{t}^{T}$ may be strongly negative. According to eq. (21) this leads to an increase in the amount of households using the $E_{t}^{p}[\cdot]$ expectations, and thus to an increase of ZLB-related animal spirits which in turn creates an upward bias in the perception of macroeconomic risk.

In the second scenario to be analyzed, the risk premium is country-specific, i.e.

$$
\zeta_{t}^{k}=\xi_{a} A_{t-1}-\xi_{y} y_{t-1}^{k}+\xi_{b}\left(b_{t-1}^{k}-\bar{b}\right)+\xi_{\pi}\left|\tilde{E}_{t}\left[\pi_{t+1}^{k}\right]-\pi^{*}\right|, \quad \text { for } \quad k=\{H, F\} .
$$


The nominal interest rate relevant for the economic decisions of households and of the government in both countries Home and Foreign is equal to the short-term policy rate plus the perceived risk premium in the financial markets, i.e.

$$
r_{t}^{k}=i_{t}+\zeta_{t}^{k}, \quad k=\{H, F\}
$$

\section{Numerical Analysis}

\subsection{Parametrization}

Since the present framework deviates in various dimensions from standard DSGE models, the choice of the model parameters is not quite straightforward. ${ }^{3}$ However, whenever possible, we use parameters widely accepted in the literature. In particular, we set the long-run trend components of consumption, government expenditures and lump-sum taxes $\mathbb{C}, \mathbb{G}$ and $\mathbb{T}$ such that in the long-run steady state private consumption to GDP ratio equals 0.8 , the government expenditures to GDP ratio 0.2 (implying thus a ratio of private to government consumption of four), and a balanced government budget, as it is standard in the literature, see e.g. Beetsma and Jensen (2005). As the steady state risky rate is equal to zero, the government debt-to-GDP ratio can be arbitrary, so we set it equal to 0.6, a standard value in the literature and also a value given by the European Maastricht Criteria. The degree of home bias is set equal to 0.9, what implies a share of imports to GDP of 0.15, under a long-run zero trade balance.

For the real interest rate elasticity of consumption demand we use the value $\sigma=2.00$ obtained by McCallum and Nelson (1999) in a New Keynesian Model. Further, we set the slope of the Phillips curve equal to 0.15 based on the empirical estimates of Goodhart and Hofmann (2005). The government sector parameters are set along the lines of the empirical estimates of Galí and Perotti (2003), namely $\phi_{g b}=0.1$, and $\phi_{g y}=0.50$ and $t_{y}=0.2$, implying total cyclical elasticity of the structural budget deficit of the order of magnitude of 0.3, see also Mayer and Stähler (2013). Concerning the monetary policy rule, we assume that $\phi_{\pi}=1.5$ and $\phi_{y}=0.5$ as it is standard in the literature, see e.g. Taylor (1993), as well as $\phi_{i}=0.7$ to allow for some degree of inertia in the policy rate. With respect to the reaction parameters in the risk equation, given the lack of empirical estimates, we set them arbitrarily to $\xi_{a}=0.1, \xi_{y}=0.05$ and $\xi_{\pi}=0.05$ as in Proaño and Lojak (2020). The value of the investors' sensitivity to fluctuations in the debt-to-GDP ratio corresponds to

\footnotetext{
${ }^{3}$ Additionally, an estimation of the present model seems quite problematic because of the limited availability of ZLB periods.
} 
Table 1: Baseline Parameterization

\begin{tabular}{lcr}
\hline \hline Parameter & Symbol & Value \\
\hline Interest rate elasticity of consumption & $\sigma^{-1}$ & 0.50 \\
Degree of home bias in consumption & $\gamma$ & 0.9 \\
Output gap elasticity of cyclical government expenditures & $\phi_{g y}$ & 0.50 \\
Government debt elasticity of cyclical government expenditures & $\phi_{g b}$ & 0.10 \\
Interest rate smoothing parameter & $\phi_{i}$ & 0.20 \\
Output gap elasticity of cyclical tax revenues & $\tau_{y}$ & 0.20 \\
Output gap elasticity of price inflation & $\kappa$ & 0.15 \\
Relative weight of ZLB gap in inflation target & $\nu_{\pi}$ & 0.0 \\
Inflation gap coefficient in interest rule & $\phi_{\pi}$ & 1.50 \\
Output gap coefficient in interest rule & $\phi_{y}$ & 0.50 \\
Long-term nominal interest rate & $i_{o}$ & 0.02 \\
Central bank's inflation target & $\pi^{\star}$ & 0.02 \\
Share of steady state consumption on output $\mathbb{C} / \mathbb{Y}$ & $\theta_{c}$ & 0.80 \\
Share of steady state government expenditures on output $\mathbb{G} / \mathbb{Y}$ & $\theta_{g}$ & 0.20 \\
Share of steady state taxes on output & $\mathbb{T} / \mathbb{Y}$ & 0.20 \\
Target Debt-to-GDP ratio & $\bar{b}$ & 0.60 \\
Degree of persistence of extrapolative consumption expectations & $\alpha_{c}$ & 0.90 \\
Intensity of choice parameter & $\mu$ & 10.0 \\
Animal spirits herding parameter in the risk premium & $\xi_{a}$ & 0.10 \\
Output gap coefficient in the market's risk perceptions & $\xi_{y}$ & 0.05 \\
Government debt coefficient in the market's risk perceptions & $\xi_{b}$ & 0.015 \\
Absolute inflation gap coefficient in risk expectations & $\xi_{\pi}$ & 0.05 \\
Home's weight in the interest rate rule & $\omega_{H}$ & 0.5 \\
\hline \hline
\end{tabular}

$\xi_{b}=0.015$ along the lines of the estimates provided by De Grauwe and Ji (2013, table 1). Table 1 summarizes all these parameter values. Finally, concerning the stochastic shocks to the system, we assume in a standard manner that all of them follow an AR(1)-process (with autoregressive coefficients equal to 0.9 ) and uniform standard deviations equal to 0.005 .

\subsection{Short-Run Dynamics}

We illustrate in Figure 1 the dynamic adjustments of the two-country model following a negative aggregate demand shock which lasts for two periods and which affects only Home for different values of $\nu_{\pi}$ (see eq.(18)). Fiscal policy is assumed to be countercyclical in both countries.

As expected, the two-period long demand shock leads to a significant fall in private con- 

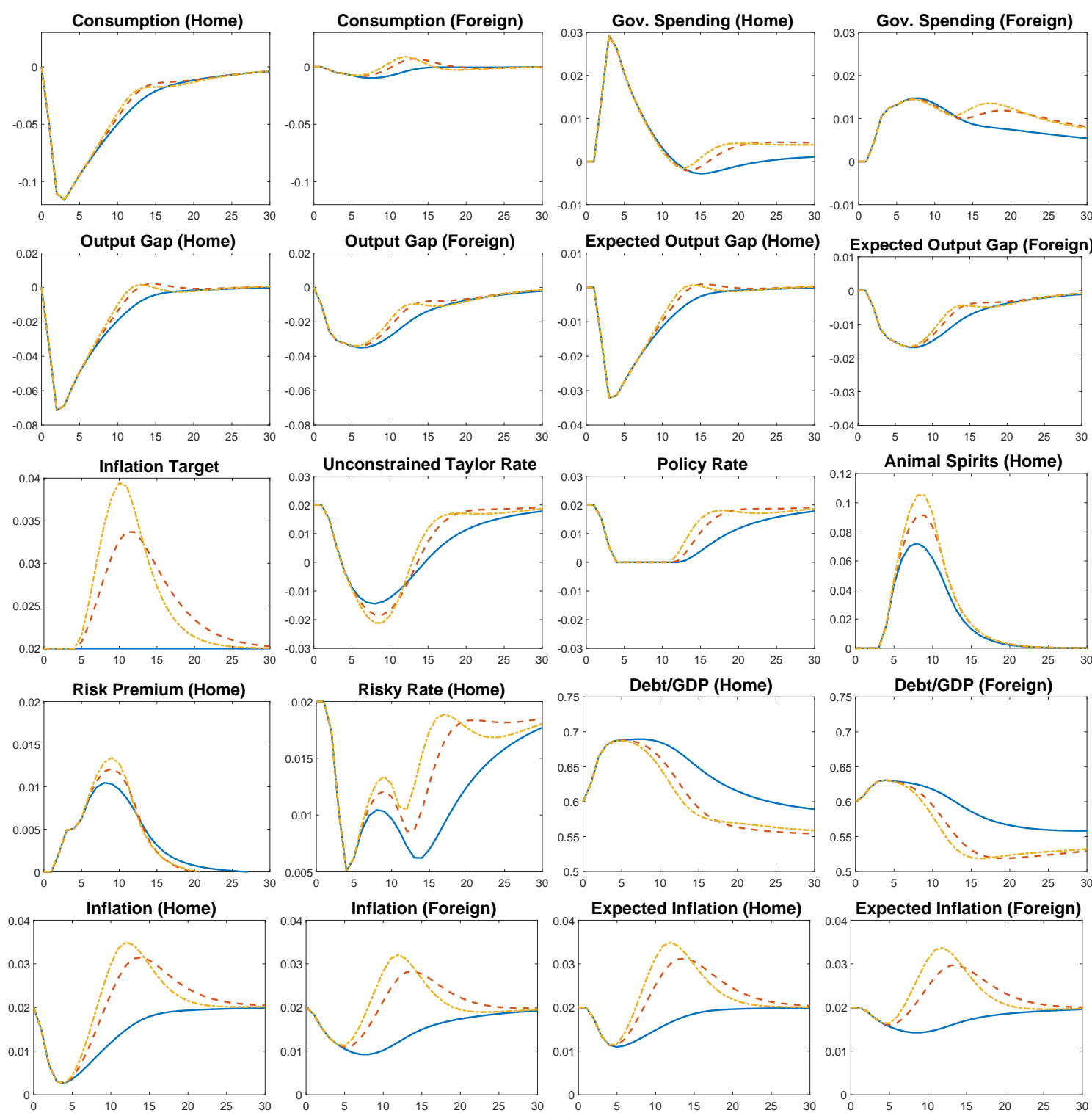

Figure 1: Adjustments after a two-period consumption shock $\epsilon_{1}^{c}=-0.05$ under a binding ZLB and a constant inflation target (solid line), a binding ZLB and a state-dependent inflation target with $\nu_{\pi}=0.25$ (dashed line) and a binding ZLB and a state-dependent inflation target with $\nu_{\pi}=0.5$ (dotted line) and the baseline parametrization described in Table 1 under risk-premium scenario 3 .

sumption which, given the significant importance of this aggregate variable, leads to a significant fall of aggregate output. This has in turn three effects: First, it leads to an increase in government expenditures due to the assumed countercyclicality in public spending. Second, it leads to a drop in price inflation through the Phillips curve relationship, as well as, third, 
to a positive trade balance (not depicted) due to the improvement in Home's terms of trade. The fall in Home's output and price inflation leads in turn to a sharp reduction in the monetary union's policy rate which, due to the cumulated magnitude of the shocks, hits the ZLB almost immediately. The decline in aggregate output leads, due to the agents' boundedlyrational expectations, to a decrease in output expectations which do not only depress private consumption further, but also lead to a higher risk premium of Home's bonds. As the ZLB policy gap increases so do the public's distrust on conventional monetary policy (the "animal spirits"), what leads to a further increase in Home's risk premium, decreasing private consumption further. As regards to fiscal policy, the increase in risk premium deteriorates the government's financing conditions, which are however rather positive due to the decrease of the reference policy rate. Finally, the Foreign country is affected by the negative aggregate demand shock in Home through two main channels: the traditional international trade channel which operates both in terms of quantity and relative prices, as well as through the actions of the monetary union-wide central bank. As previously discussed, these are two: First, the decrease in the policy rate up to the point where the ZLB binds and second, the increase in the inflation target. Particularly the effect of the latter on Foreign's macroeconomic development becomes evident in the evolution of its private consumption: For higher values of $\nu_{\pi}$, and thus for temporarily higher inflation targets, the decrease in private consumption in the Foreign region is not only much shorter-lived than under a constant inflation target; private consumption even increases above its steady state value for some periods before returning its steady state.

While for the standard case of a constant inflation target inflation expectations remain below the $2 \%$ target for a significant amount of time, when the inflation target is temporarily increased according to eq.(18), and the new target is believed at least by a (varying) fraction of agents, aggregate inflation expectation rise, as illustrated by third and fourth panels in the fourth graph row in Figure 1. Indeed, even though a higher fraction of agents follow the persistent expectation rule, the increase in the inflation target leads to an increase in aggregate expectation which reduces the real interest rate, leading to a faster recovery both in terms of private consumption and output.

It is worthwhile noting that for a higher value of $\nu_{\pi}$, and thus for higher inflation targets, the evaluation of what would be the Taylor-rate varies too, modifying thus the ZLB gap, the risk premium and the relative weights in the aggregate expectations. These different effects are actually counterproductive: While the increase in $\omega_{t}^{p}$ due to the larger ZLB policy gap undermines the credibility of the central bank inflation target (as more agents rely on the backward-looking rule), the increase in the animal spirits and in Home's risk premium leads 
to a worsening of the financial conditions of the private and public sector. For the current calibration, however, the positive effect of a higher inflation target dominates.

\subsection{Monte-Carlo Analysis}

As next we ran a Monte Carlo experiment where we shocked both economies with private consumption (demand) and price inflation (supply) shocks in each period for 500 periods, repeating this experiment 10.000 times using the same parameters as described in Table 1 and varying only the parameter $\nu_{\pi}$, i.e. the relative importance of the state-dependent component in the inflation target, see eq.(18). The objective of this analysis is to assess the mediumterm performance of a state-dependent inflation target, as one common argument in the literature has been that (constantly) higher inflation targets are likely to be welfare-imparing due to the increase in inflation volatility they may lead to. We evaluate the performance of state-dependent inflation targets in terms of the median and the standard deviations of the key macroeconomic variables, as well as through the number periods where the economy is constrained by the ZLB (as percent of the total number of simulated periods).

Table 2: Simulated moments: Common risk-premium scenario

\begin{tabular}{rrcccccc}
\hline \hline & & $\nu_{\pi}=0.00$ & $\nu_{\pi}=0.20$ & $\nu_{\pi}=0.40$ & $\nu_{\pi}=0.60$ & $\nu_{\pi}=0.80$ & $\nu_{\pi}=1.00$ \\
\hline Output Gap Home: & Median & -0.137 & -0.081 & -0.080 & -0.080 & -0.080 & -0.079 \\
& Std. Dev. & 2.911 & 2.914 & 2.914 & 2.912 & 2.911 & 2.911 \\
Output Gap Foreign: $\quad$ Median & -0.097 & -0.059 & -0.058 & -0.058 & -0.058 & -0.058 \\
& Std. Dev. & 2.932 & 2.934 & 2.932 & 2.931 & 2.930 & 2.930 \\
Inflation Home: $\quad$ Median & 1.973 & 2.009 & 2.009 & 2.009 & 2.009 & 2.009 \\
& Std. Dev. & 0.887 & 0.883 & 0.878 & 0.875 & 0.873 & 0.871 \\
Inflation Foreign: $\quad$ Median & 1.972 & 2.010 & 2.010 & 2.010 & 2.010 & 2.010 \\
Std. Dev. & 0.887 & 0.884 & 0.879 & 0.876 & 0.874 & 0.873 \\
Risky Rate Home: $\quad$ Median & 2.046 & 2.071 & 2.069 & 2.069 & 2.069 & 2.069 \\
& Std. Dev. & 0.939 & 0.944 & 0.941 & 0.938 & 0.936 & 0.935 \\
Risky Rate Foreign: $\quad$ Median & 1.932 & 1.964 & 1.964 & 1.965 & 1.965 & 1.965 \\
& Std. Dev. & 0.975 & 0.977 & 0.973 & 0.969 & 0.968 & 0.966 \\
Debt/GDP Home: $\quad$ Median & 63.267 & 62.535 & 62.509 & 62.499 & 62.492 & 62.487 \\
Std. Dev. & 7.940 & 7.870 & 7.853 & 7.844 & 7.839 & 7.836 \\
Debt/GDP Foreign: $\quad$ Median & 60.032 & 59.664 & 59.668 & 59.666 & 59.667 & 59.666 \\
& Std. Dev. & 7.801 & 7.924 & 7.903 & 7.896 & 7.892 & 7.889 \\
No. ZLB (\%) & 2.800 & 2.600 & 2.600 & 2.600 & 2.400 & 2.400 \\
\hline \hline
\end{tabular}

Table 2 illustrates the results of this experiment assuming the values for the risk premium parameters $\xi_{a}, \xi_{b}$ and $\xi_{\pi}$ from Table 1 under the first scenario described by eq. (19). First and foremost, we find that the median output gap in both Home and Foreign over all simulated 
periods tends to be less negative for higher values of $\nu_{\pi}$, indicating that a more accommodating setting of the inflation target may be beneficial in terms of macroeconomic stabilization. Interestingly, while the difference in the Home's and Foreign's output gap medians between $\nu_{\pi}=0.00$ and $\nu_{\pi}=0.20$ is relatively large, the difference between $\nu_{\pi}=0.20$ and $\nu_{\pi}=$ $0.40 \ldots 1.00$ is negligible. Similarly, this result extends also to the median inflation rates in Home and Foreign: an increase from $\nu_{\pi}=0.00$ to $\nu_{\pi}=0.20$ leads to a slight increase in these variables, but again the difference between $\nu_{\pi}=0.20$ and $\nu_{\pi}=0.40 \ldots 1.00$ is negligible. It is noteworthy in this context that the median inflation rates are also for $\nu_{\pi}>0$ not above the long-run target of $2 \%$. We also compute the median number of periods where the ZLB became a binding constraint in our Monte Carlo simulation. As it can be clearly observed in the last row, the median number of ZLB periods (as percent of the total number of periods) for the considered calibration is $2.8 \%$ for a constant inflation rate $\nu_{\pi}=0.0$, and $2.60 \%$ for $\nu_{\pi}=0.2$ and $2.8 \%$ for $\nu_{\pi}=0.4$. These results suggest that the gains from a more flexible inflation target may be nonlinear, and that a slight increase in its flexibility may "do the trick". Concerning the simulated standard deviations of the key macroeconomic variables of the model in the baseline scenario, Table 2 shows that the implementation of a statedependent inflation target does not lead to a significant increase in the output gap volatility, and that the standard deviations of the inflation rates, risky rates and the debt-to-GDP ratio actually decrease with higher values of $\nu_{\pi}$. If social welfare was associated with output gap and inflation gap volatility, higher values of $\nu_{\pi}$ would thus not be detrimental in social welfare terms. Last but not least, as the last row in Table 2 shows, the number of ZLB periods (as percentage of the total number of simulations) slightly decreases with an increasing $\nu_{\pi}$ in line with the argumentation by Blanchard et al. (2013) and others.

Table 3 reports the simulated moments obtained through the Monte Carlo experiment for the second scenario of country-specific risk premia assuming exactly the same shocks as in the previous scenario.

First and foremost, the median output gaps of Home and Foreign in the country-specific risk scenario are significantly more negative than in the common-risk scenario, what clearly corroborates the risk-sharing advantages of a monetary union, see e.g. Proaño et al. (2014). Second, and in this context, the number of ZLB periods as percent of the total number of periods (last row of Table 3) in this country-specific risk premium case is about double as high as in the previous case of a common risk-premium. Third, as in the previous scenario, an increase of $\nu_{\pi}$ from 0.0 to 0.20 leads to a larger increase of the medians of the output gaps of both countries than further increases, suggesting that the benefits of a more flexible inflation target are not linear. Further, the median inflation rates of both countries are also smaller 
Table 3: Simulated moments: Country-specific risk premium scenario

\begin{tabular}{rrcccccc}
\hline \hline \multicolumn{1}{c}{} & & $\nu_{\pi}=0.00$ & $\nu_{\pi}=0.20$ & $\nu_{\pi}=0.40$ & $\nu_{\pi}=0.60$ & $\nu_{\pi}=0.80$ & $\nu_{\pi}=1.00$ \\
\hline Output Gap Home: & Median & -0.295 & -0.244 & -0.242 & -0.241 & -0.238 & -0.238 \\
& Std. Dev. & 2.938 & 2.955 & 2.950 & 2.948 & 2.946 & 2.945 \\
Output Gap Foreign: $\quad$ Median & -0.276 & -0.230 & -0.225 & -0.223 & -0.223 & -0.221 \\
& Std. Dev. & 2.946 & 2.958 & 2.954 & 2.951 & 2.949 & 2.947 \\
Inflation Home: $\quad$ Median & 1.936 & 1.986 & 1.984 & 1.983 & 1.982 & 1.981 \\
& Std. Dev. & 0.878 & 0.895 & 0.890 & 0.885 & 0.881 & 0.877 \\
Inflation Foreign: $\quad$ Median & 1.936 & 1.987 & 1.985 & 1.982 & 1.982 & 1.981 \\
& Std. Dev. & 0.877 & 0.896 & 0.890 & 0.884 & 0.881 & 0.878 \\
Risky Rate Home: $\quad$ Median & 1.978 & 2.010 & 2.008 & 2.005 & 2.004 & 2.003 \\
& Std. Dev. & 0.941 & 0.954 & 0.951 & 0.947 & 0.944 & 0.943 \\
Risky Rate Foreign: $\quad$ Median & 1.976 & 2.012 & 2.009 & 2.007 & 2.006 & 2.005 \\
& Std. Dev. & 0.941 & 0.955 & 0.952 & 0.947 & 0.945 & 0.943 \\
Debt/GDP Home: $\quad$ Median & 63.917 & 63.358 & 63.333 & 63.297 & 63.285 & 63.259 \\
Std. Dev. & 10.450 & 10.508 & 10.478 & 10.458 & 10.458 & 10.448 \\
Debt/GDP Foreign: $\quad$ Median & 63.873 & 63.218 & 63.178 & 63.150 & 63.133 & 63.112 \\
& Std. Dev. & 10.421 & 10.493 & 10.460 & 10.442 & 10.435 & 10.420 \\
No. ZLB (\%) & 5.400 & 4.400 & 4.200 & 4.000 & 4.000 & 3.800 \\
\hline \hline
\end{tabular}

than in the common-risk-case, a result that is obviously linked with the lower median output gaps. Finally, while the median government debt-to-GDP ratios are higher and feature also a larger standard deviation in this country-specific risk scenario than in the common risk scenario, they (marginally) decrease with larger values of $\nu_{\pi}$. A flexible inflation target may thus also assist the macroeconomic stabilization by the fiscal policy of both countries.

\section{Robustness Analysis}

The following 3-dimensional graphs in Figures 2 and 3 summarize the results of Monte Carlo simulation of the two-country model for varying parameters of $\nu_{\pi}$ (as it was done in the previous section) as well as of $\xi_{a}, \xi_{y}, \xi_{b}$ and $\xi_{\pi}$, the parameters in the risk premium equation (19) for scenario 1 and (22) for scenario 2 , respectively.

In general terms, the rather smooth shape of the 3-dimensional surfaces depicted in both Figures 2 and 3 suggest that the results discussed in the previous sections are fairly robust to the respective parameter changes. This is also true for all other robustness figures contained in the Appendix of this paper.

Nonetheless, the steady positive or negative surface slopes in some cases, though of a very small numerical dimension, deliver some additional insights worth discussing. First, as discussed in the previous section, a slight flexibility in the inflation target in both scenarios 

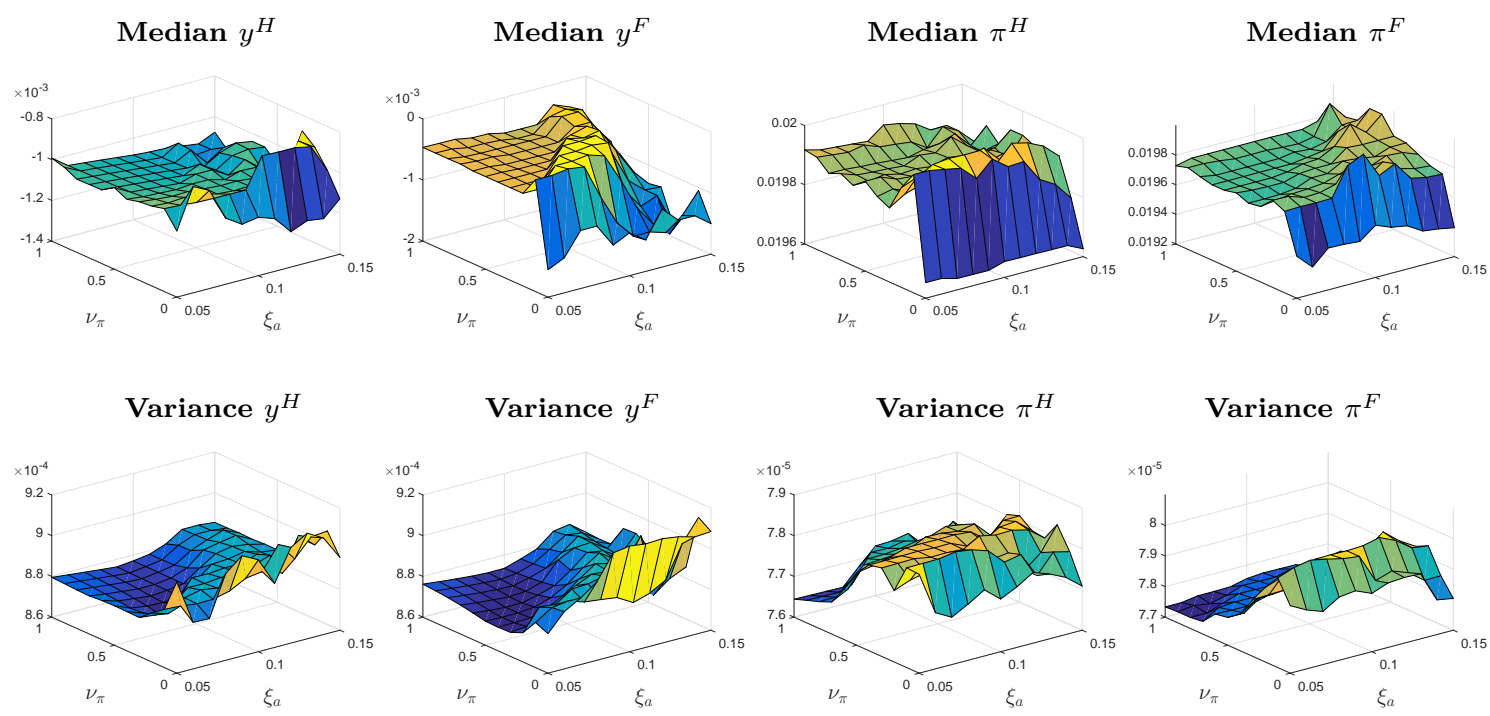

Figure 2: Robustness analysis $\xi_{a}$, Scenario 1.

leads to a small increase in the simulated median inflation rates in Home and Foreign, as well, though to a much lesser extent, in the median output gaps of both countries. Higher values of $\nu_{\pi}$ do not lead to significant changes in any of these variables in both scenarios, though. Further, it is also noteworthy that the volatility of the inflation rates in Home and Foreign seems to increase when $\nu_{\pi}$ becomes initially positive only to decrease further as $\nu_{\pi} \rightarrow 1$, this drop occurring at lower values of $\nu_{\pi}$ when $\xi_{a}$ is lower. Even though the magnitude of these effects is quite small, they highlight nonetheless the importance of the risk premium terms for the performance of a flexible inflation target.

\section{Concluding Remarks}

The ZLB has passed from being a theoretical scenario to become a binding constraint for many countries in recent years. This has led the profession to rethink how macroeconomic both monetary as well as fiscal - policy should be designed and conducted.

In this paper we focus on a dimension of the ZLB not yet explored in the literature: how its existence may constrain the effectiveness of monetary policy in a monetary union such as the euro area. In our view, this is by no means a trivial issue: as the loss of an independent monetary policy due to the membership in a monetary union is linked with a significant loss of macroeconomic flexibility for each member economy, the ZLB may be even more binding than for economies with an own currency and monetary policy. 

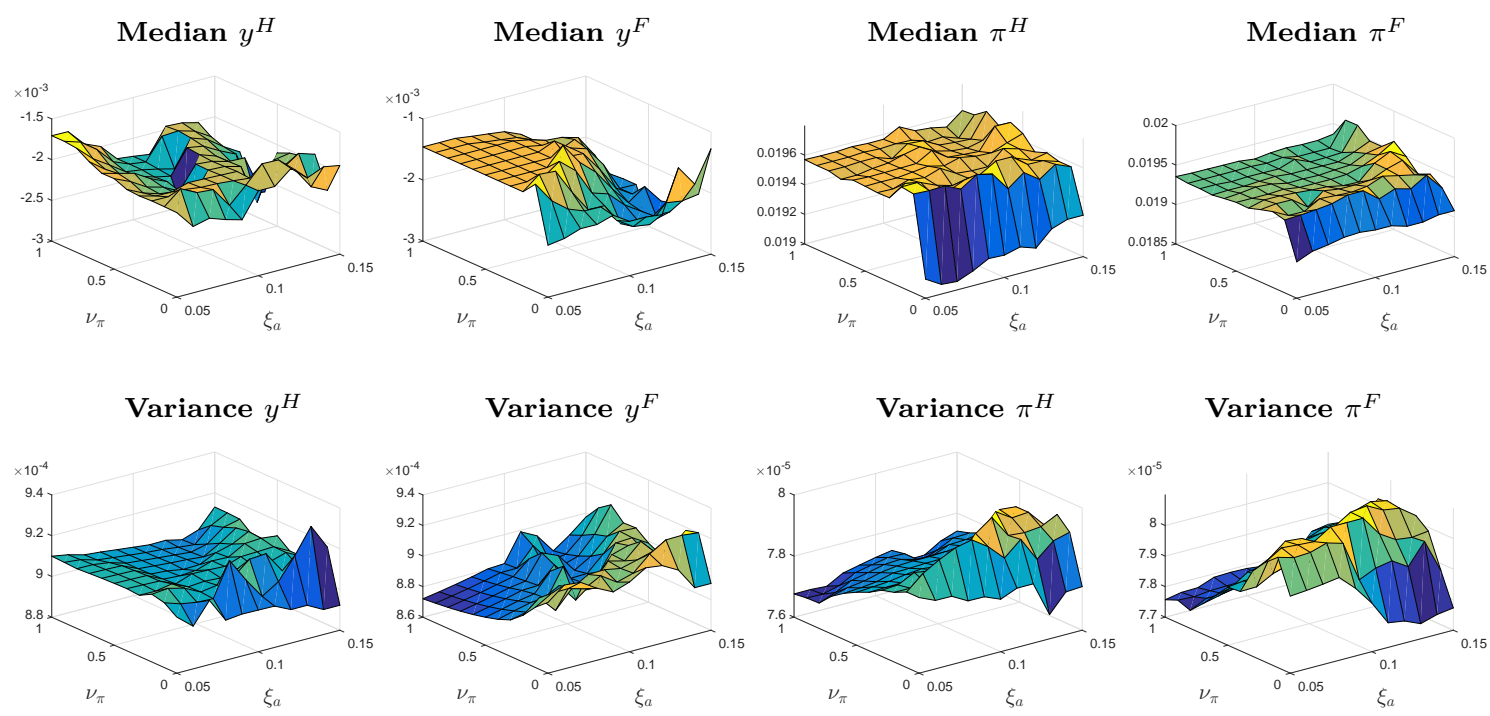

Figure 3: Robustness analysis $\xi_{a}$, Scenario 2 .

Our numerical simulations show that this is not only the case, but that the risk-sharing dimension of monetary unification may be particularly important if the markets' risk perceptions are linked with the foregone accommodation of conventional monetary policy resulting from a binding ZLB constraint. A more thorough examination of the macroeconomic and financial channels outlined in this paper in a medium scale monetary union model such as Beetsma and Jensen (2005) with and without rational expectations as in Bertasiute et al. (2020) seems to be thus a promising venue for future research.

\section{References}

Adrian, T., Moench, E. and Shin, H. S. (2010), 'Macro risk premium and intermediary balance sheet quantities', IMF Economic Review 58, 179-207.

Ball, L. M. (2013), 'The case for four percent inflation', Central Bank Review 13(2), 17-31.

Beetsma, R. M. and Jensen, H. (2005), 'Monetary and fiscal policy interactions in a microfounded model of a monetary union', Journal of International Economics 67, 320-352.

Bernanke, B. (2017), Monetary policy in a new era. Paper prepared for conference on Rethinking Macroeconomic Policy, Peterson Institute, Washington DC, October 12-13, 2017.

Bertasiute, A., Massaro, D. and Weber, M. (2020), 'The behavioral economics of currency 
unions: Economic integration and monetary policy', Journal of Economic Dynamics 83 Control 112, 103850.

Bertasuite, A., Massaro, D. and Weber, M. (2020), 'The behavioral economics of currency unions: Economic integration and monetary policy', Journal of Economic Dynamics \& Control 112, 103850.

Blanchard, O., Dell'Ariccia, G. and Mauro, P. (2010), 'Rethinking macroeconomic policy', Journal of Money, Credit and Banking 42(s1), 199-215.

Blanchard, O., Dell'Ariccia, G. and Mauro, P. (2013), Rethinking macro policy ii: Getting granular, Staff Discussion Notes 13/3, International Monetary Fund.

Brock, W. and Hommes, C. (1997), 'A rational route to randomness', Econometrica 65, 1059 -1095 .

Chung, H., Laforte, J.-P., Reifschneider, D. and Williams, J. C. (2012), 'Have we underestimated the likelihood and severity of zero lower bound events?', Journal of Money, Credit and Banking 44, 47-82.

Coibion, O., Gorodnichenko, Y. and Wieland, J. (2012), 'The optimal inflation rate in new keynesian models: Should central banks raise their inflation targets in light of the zero lower bound?', Review of Economic Studies 79(4), 1371-406.

De Grauwe, P. (2012), 'Booms and busts in economic activity: A behavioral explanation', Journal of Economic Behavior and Organization 83(3), 484-501.

De Grauwe, P. and Ji, Y. (2013), 'Self-fulfilling crises in the eurozone: An empirical test', Journal of International Money and Finance 34, 15-36.

De Grauwe, P. and Ji, Y. (2019), 'Inflation targets and the zero lower bound in a behavioral macroeconomic model', Economica 86(342), 262-299.

Dordal i Carreras, M., Coibion, O., Gorodnichenko, Y. and Wieland, J. (2016), 'Infrequent but long-lived zero lower bound episodes and the optimal rate of inflation', American Review of Economics 8, 497-520.

Eggertsson, G. B. and Woodford, M. (2003), 'The zero bound on interest rates and optimal monetary policy', Brookings Papers on Economic Activity 34(1), 139-235. 
Evans, C. (2010), 'Monetary policy in a low-inflation environment: Developing a statecontingent price-level target', Speech at the Federal Reserve Bank of Boston's 55th Economic Conference, Revisiting Monetary Policy in a Low Inflation Environment.

Galí, J. and Perotti, R. (2003), 'Fiscal policy and monetary integration in europe', Economic Policy 18(37), 533-572.

Goodhart, C. and Hofmann, B. (2005), 'The Phillips Curve, the IS curve and monetary transmission: Evidence for the US and the euro area', CESifo Economic Studies 51(4), 757775 .

Jaumotte, F. and Sodsriwiboon, P. (2010), Current account imbalances in the southern euro area, IMF Working Papers 10/139, International Monetary Fund.

Kiley, M. T. and Roberts, J. M. (2017), 'Monetary policy in a low interest rate world', Brookings Papers on Economic Activity pp. 317-396.

Krugman, P. R. (1998), 'It's baaack: Japan's slump and the return of the liquidity trap', Brookings Papers on Economic Activity 29(2), 137-206.

Mayer, E. and Stähler, N. (2013), 'The debt brake: business cycle and welfare consequences of Germany's new fiscal policy rule', Empirica 40, 39-74.

McCallum, B. T. and Nelson, E. (1999), Performance of operational policy rules in an estimated semiclassical structural model, in 'Monetary Policy Rules', NBER Chapters, National Bureau of Economic Research, Inc, pp. 15-56.

Proaño, C. and Lojak, B. (2017), Macroeconomic risk, fiscal policy rules and aggregate volatility in asymmetric currency unions: A behavioral perspective, in A. Bökemeier, B. \& Greiner, ed., 'Inequality and Finance in Macrodynamics', Vol. 23 of Dynamic Modeling and Econometrics in Economics and Finance Series, Springer, New York, pp. 221-242.

Proaño, C. R. and Lojak, B. (2020), 'Animal spirits, risk premia and monetary policy at the zero lower bound', Journal of Economic Behavior and Organization 171, 221-233.

Proaño, C. R., Schoder, C. and Semmler, W. (2014), 'Financial stress, sovereign debt and economic activity in industrialized countries: Evidence from dynamic threshold regressions', Journal of International Money and Finance 45, 17-37.

Quint, D. and Rabanal, P. (2014), 'Monetary and macroprudential policy in an estimated DSGE model of the euro area', International Journal of Central Banking 10(2), 169-236. 
Schmitt-Grohe, S. and Uribe, M. (2010), The optimal rate of inflation, in B. M. Friedman and M. Woodford, eds, 'Handbook of Monetary Economics', Vol. 3, Elsevier, chapter 13, pp. $653-722$.

Taylor, J. B. (1993), 'Discretion versus policy rules in practice', Carnegie-Rochester Conference Series on Public Policy 39, 195-214. 


\section{A Appendix}
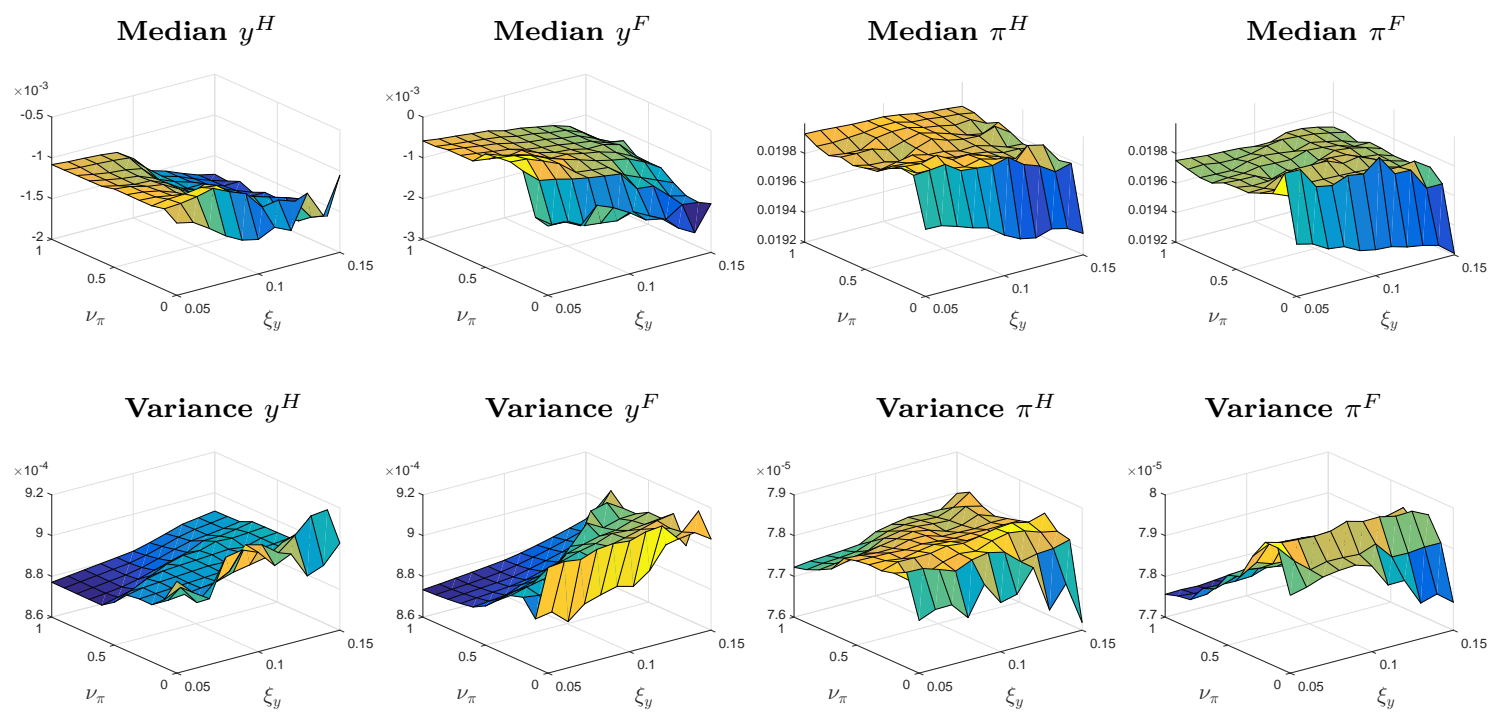

Figure 4: Robustness analysis $\xi_{y}$, Scenario 1.
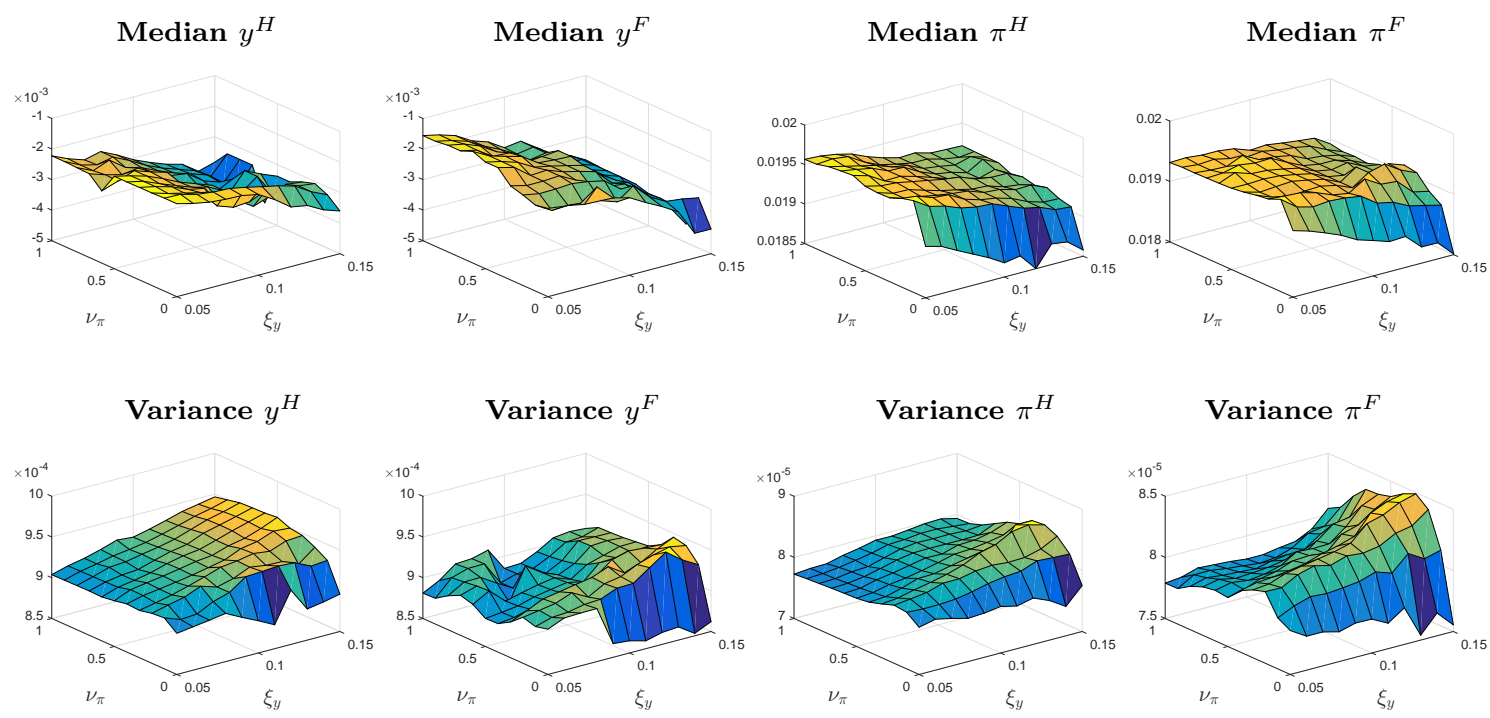

Figure 5: Robustness analysis $\xi_{y}$, Scenario 2 . 

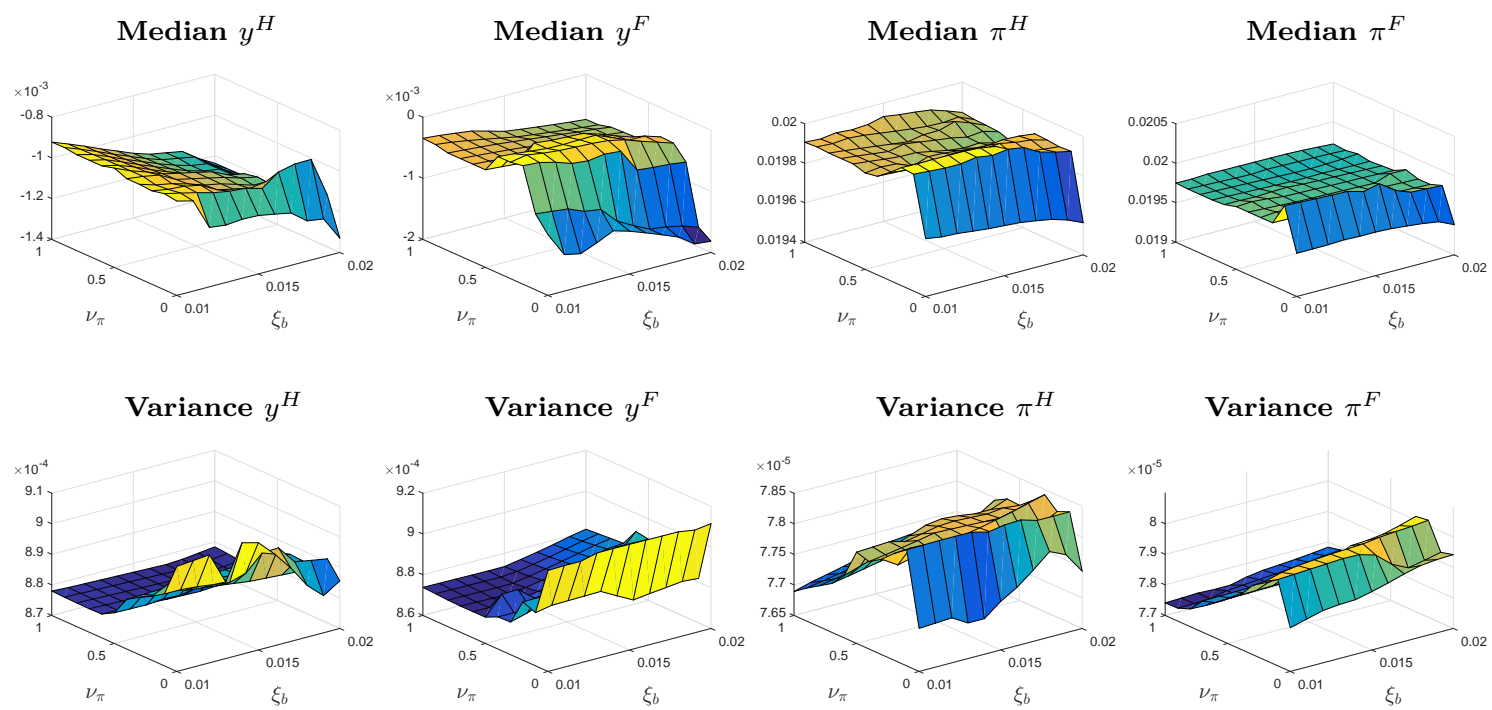

Figure 6: Robustness analysis $\xi_{b}$, Scenario 1 .
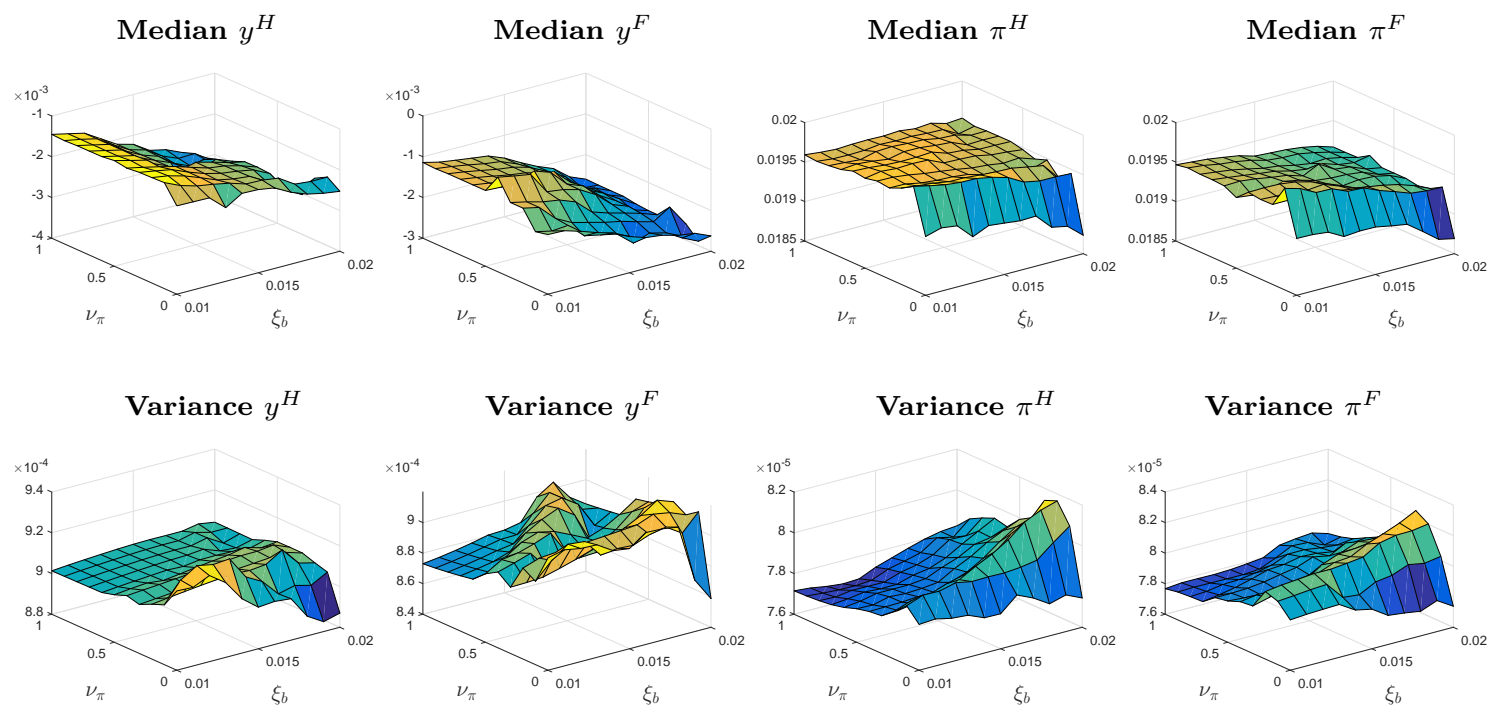

Figure 7: Robustness analysis $\xi_{b}$, Scenario 2 . 

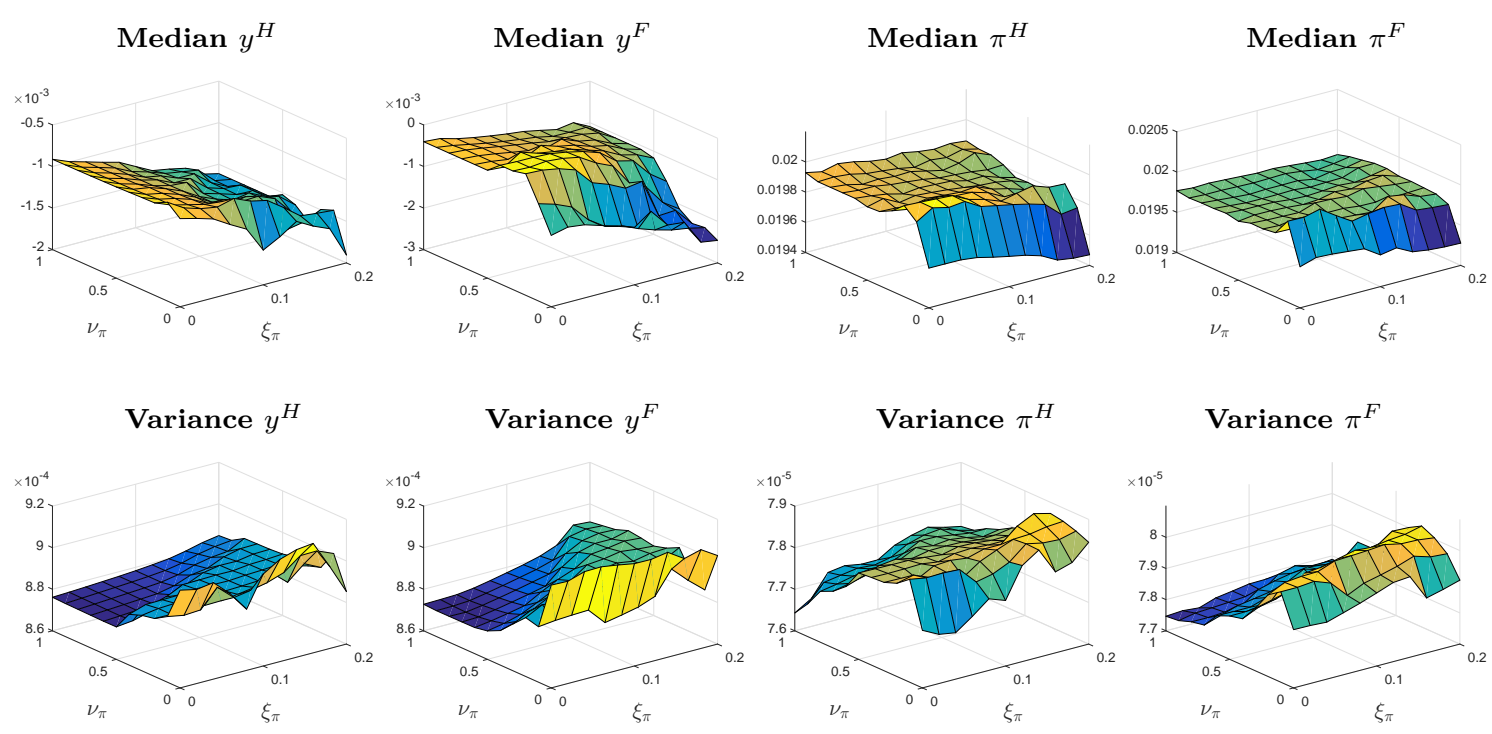

Figure 8: Robustness analysis $\xi_{\pi}$, Scenario 1.
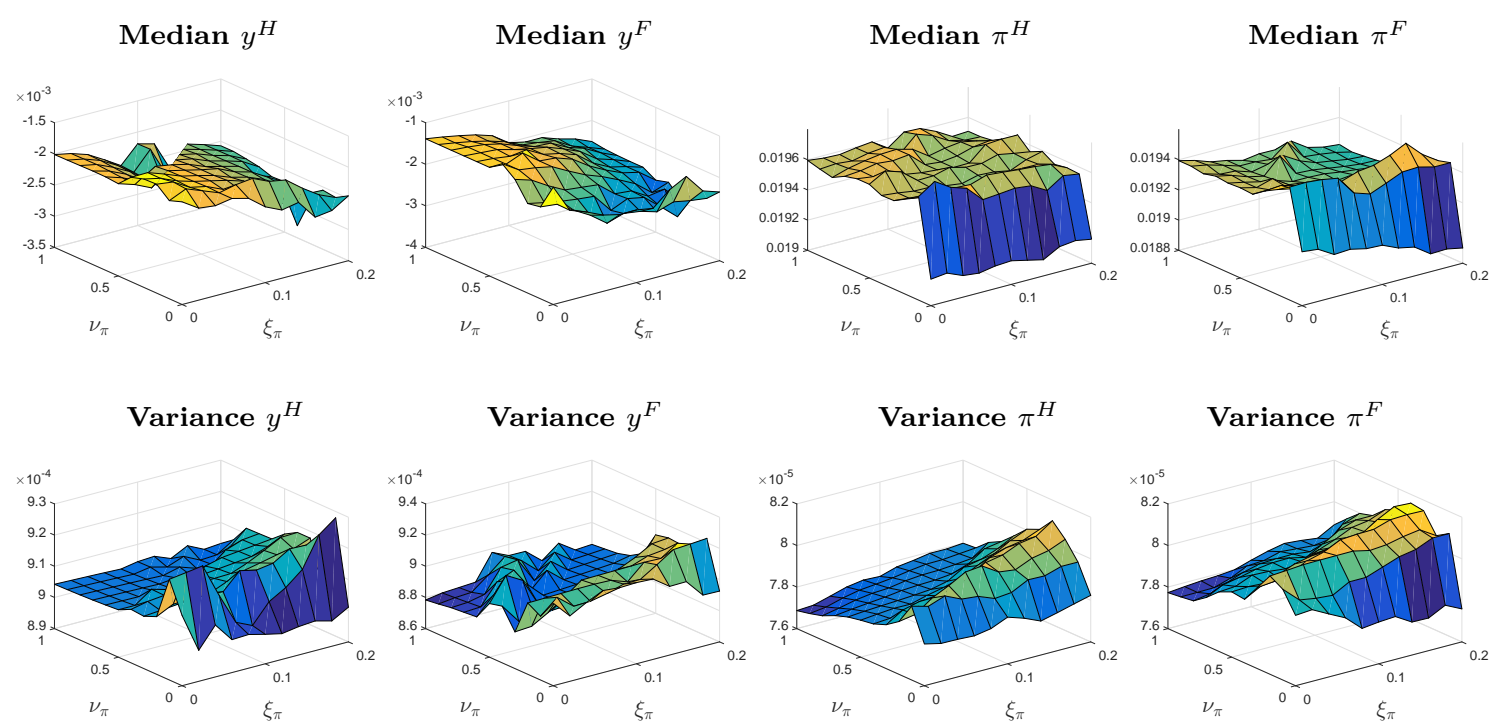

Figure 9: Robustness analysis $\xi_{\pi}$, Scenario 2 . 